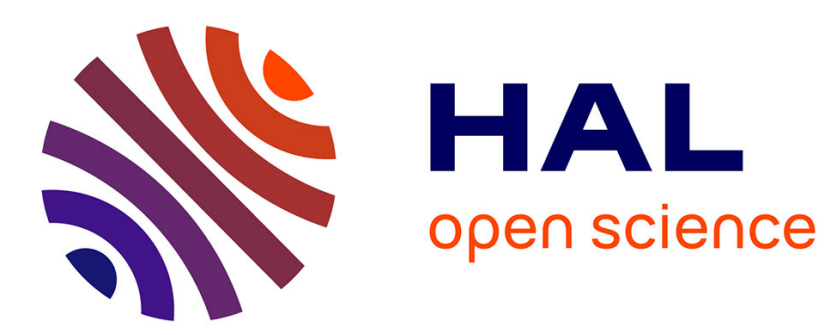

\title{
Study of unsteady convection through simultaneous velocity and interferometric measurements
}

\author{
P. Bergé, M. Dubois
}

\section{To cite this version:}

P. Bergé, M. Dubois. Study of unsteady convection through simultaneous velocity and interferometric measurements. Journal de Physique Lettres, 1979, 40 (19), pp.505-509. 10.1051/jphyslet:019790040019050500 . jpa-00231675

\section{HAL Id: jpa-00231675 https://hal.science/jpa-00231675}

Submitted on 1 Jan 1979

HAL is a multi-disciplinary open access archive for the deposit and dissemination of scientific research documents, whether they are published or not. The documents may come from teaching and research institutions in France or abroad, or from public or private research centers.
L'archive ouverte pluridisciplinaire HAL, est destinée au dépôt et à la diffusion de documents scientifiques de niveau recherche, publiés ou non, émanant des établissements d'enseignement et de recherche français ou étrangers, des laboratoires publics ou privés. 


\title{
LE JOURNAL DE PHYSIQUE-LETTRES
}

\section{Study of unsteady convection through simultaneous velocity and interferometric measurements}

\author{
P. Bergé and M. Dubois \\ Service de Physique du Solide et de Résonance magnétique, DPh-G/PSRM, CEN, Saclay, B.P. nº 2, 91190 Gif-sur-Yvette, France
}

(Reçu le 2 juillet 1979, accepté le 20 aô̂t 1979)

\begin{abstract}
Résumé. - Nous présentons un système optique très simple, qui permet de mesurer simultanément la vitesse au sein d'un fluide en convection et la carte des isogradients de température. La simultanéité de ces deux mesures permet une approche beaucoup plus complète des phénomènes convectifs, particulièrement de ceux dépendants du temps. Nous avons appliqué cette méthode à l'instabilité de Rayleigh-Bénard et avons pu mettre ainsi en évidence le mécanisme physique, responsable du comportement oscillant, observé dans une petite boîte.
\end{abstract}

\begin{abstract}
A very simple optical device is proposed, which enables the velocity in a convective fluid, and the map of the temperature isogradients to be simultaneously measured. The simultaneity of these two measurements is an important step in the understanding of unsteady phenomena. This fact is illustrated by the study of the time oscillatory behaviour of the motion observed in a fluid confined in a small box, and submitted to the RayleighBénard instability.
\end{abstract}

The usefulness of local optical velocity measurements for the understanding of Rayleigh-Bénard convection has been widely demonstrated $[1,2,3]$. Nevertheless, up to now, this powerful technique has only provided local information on velocity behaviour at a given time. In contrast with this technique, a full map of the temperature perturbations can be obtained through interferometric measurements [4], and, then, usefully combined with velocity measurements. An alternative differential interferometric method, using Wollaston prisms, has been proposed $[5,6]$ and widely used in the case of RayleighBénard convection $[7,8]$. In this letter, we present a much simpler optical system which provides differential interferogrammes; moreover, the simultaneous use of this interferometric technique with laser Doppler velocimetry on the same sample, is a very powerful method; this point is illustrated in the study of unsteady convective motion, from which new information on the mechanism of the oscillatory regime in high Prandtl number fluids is obtained.

Background. - Rayleigh-Bénard convection is the problem of a simple, dilatable fluid, confined between two highly conducting rigid horizontal plates and submitted to a thermal gradient $\Delta T / d$ where $\Delta T$ is the temperature difference applied between the plates and $d$ is the depth of the fluid layer. If this gradient, parallel to the gravity axis, is higher than a certain threshold, regular convective motions set in. A good stability parameter is the Rayleigh number $R a$

$$
R a=\frac{\alpha g \Delta T d^{3}}{v D_{\mathrm{T}}}
$$

where $g$ is the gravitational acceleration and $\alpha, v$ and $D_{\mathrm{T}}$ are respectively the volume expansion coefficient, the kinematic viscosity and the thermal diffusivity of the fluid.

If $R a$ is lower than a critical value $R a_{\mathrm{c}}$, the fluid remains at rest. On the contrary, if $R a>R a_{\mathrm{c}}$, the system is unstable and convective velocity is present and spatially organized in rolls. It was recently found $[3,9,10]$ that, by increasing the Rayleigh number, the following states appear successively :

1) Steady two dimensional rolls at $R a_{\mathrm{c}}$.

2) Steady three dimensional rolls at $R a^{\mathrm{II}}$.

3) Monoperiodic time oscillation of the velocity at $R a_{\text {osc }}$.

4) Biperiodic oscillations of the velocity at $R a_{\text {bip }}$.

5) First appearance of chaotic behaviour of the velocity i.e. turbulence at $R a_{\mathrm{T}}$.

In fact, the existence and the threshold of some of these steps in this cascade towards turbulence depend on the geometry of the box confining the fluid, and also on the actual structure $[10,16]$. In a small 
box, with an aspect ratio (ratio between the horizontal extension to the depth of the layer) $\Gamma=2$, all the sequences described above may be found in high Prandtl number fluid $\left({ }^{1}\right)$ [10] $\left(\operatorname{Pr}=v / D_{\mathrm{T}}\right)$. The experiments reported here use this geometry.

Experimental conditions. - The convective fluid is silicone oil with viscosity $\eta=0.11$ stoke at $20^{\circ} \mathrm{C}$, $D_{\mathrm{T}}=7.64 \times 10^{-4} \mathrm{~cm}^{2} \mathrm{~s}^{-1}$ and $P r \simeq 130$. It is contained in a rectangular plexiglass frame (fig. 1); the dimensions of the fluid layer are $d=1.25 \mathrm{~cm}$, $L_{x}=2.50 \mathrm{~cm}, L_{y}=1.50 \mathrm{~cm}$. The top and the bottom of the cell consist of massive copper plates thermally regulated to within $10^{-2}{ }^{\circ} \mathrm{C}$. In the experiment described here, we have in fact two identical cells, filled with the same oil and inserted between the same copper plates, so that their axes $X^{\prime} X$ are perpendiular ; in this way we were able to observe the differential interferogrammes along the two principal axes $X^{\prime} X$ and $Y^{\prime} Y$ of the convective motion.

The laser Doppler velocimeter is of the conventional type and has already been described [13]. The instantaneous Doppler frequency $f_{\mathrm{d}}$ is directly measured with an automatic counter; its time variations can be Fourier analysed with an FFT analyser working

( ${ }^{1}$ And also in low Prandtl convection, except for the second step $[11,12]$.

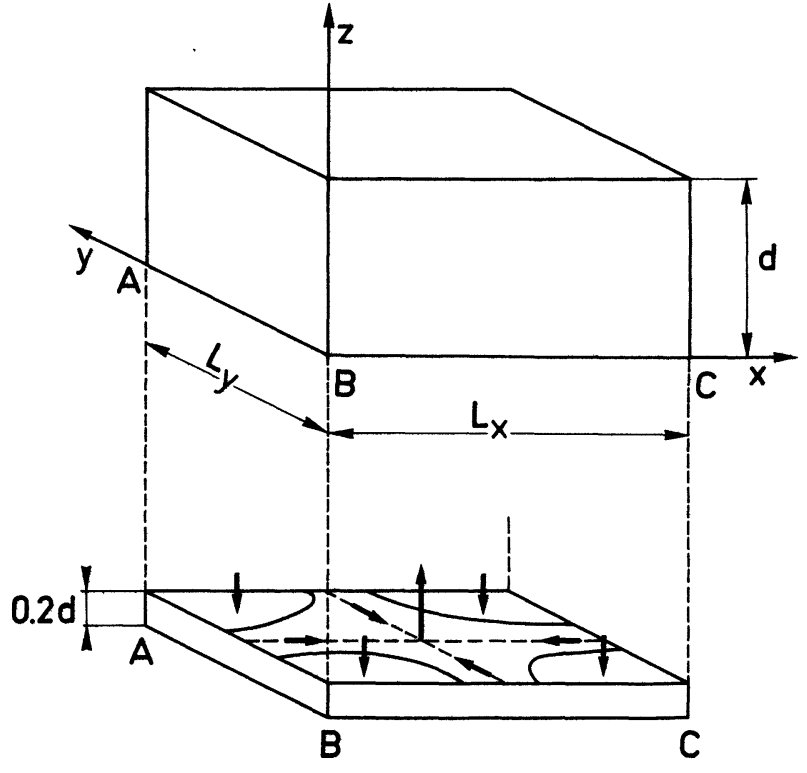

Fig. 1. - Scheme of the experimental cell used : $d=1.25 \mathrm{~cm}$, $L_{x}=2.5 \mathrm{~cm}$ and $L_{y}=1.5 \mathrm{~cm}$. At the bottom, scheme of the velocity field at the height $Z=0.2 d$. The curved horizontal full lines represent the lines where $V_{z}=0$.

at a very low frequency. In the geometry used in these experiments, the frequency $f_{\mathrm{d}}$ corresponds to the vertical velocity component $V_{z}$, measured at the midheight of the cell $(Z=d / 2)$.

The differential interferometer is very simple (fig. 2).

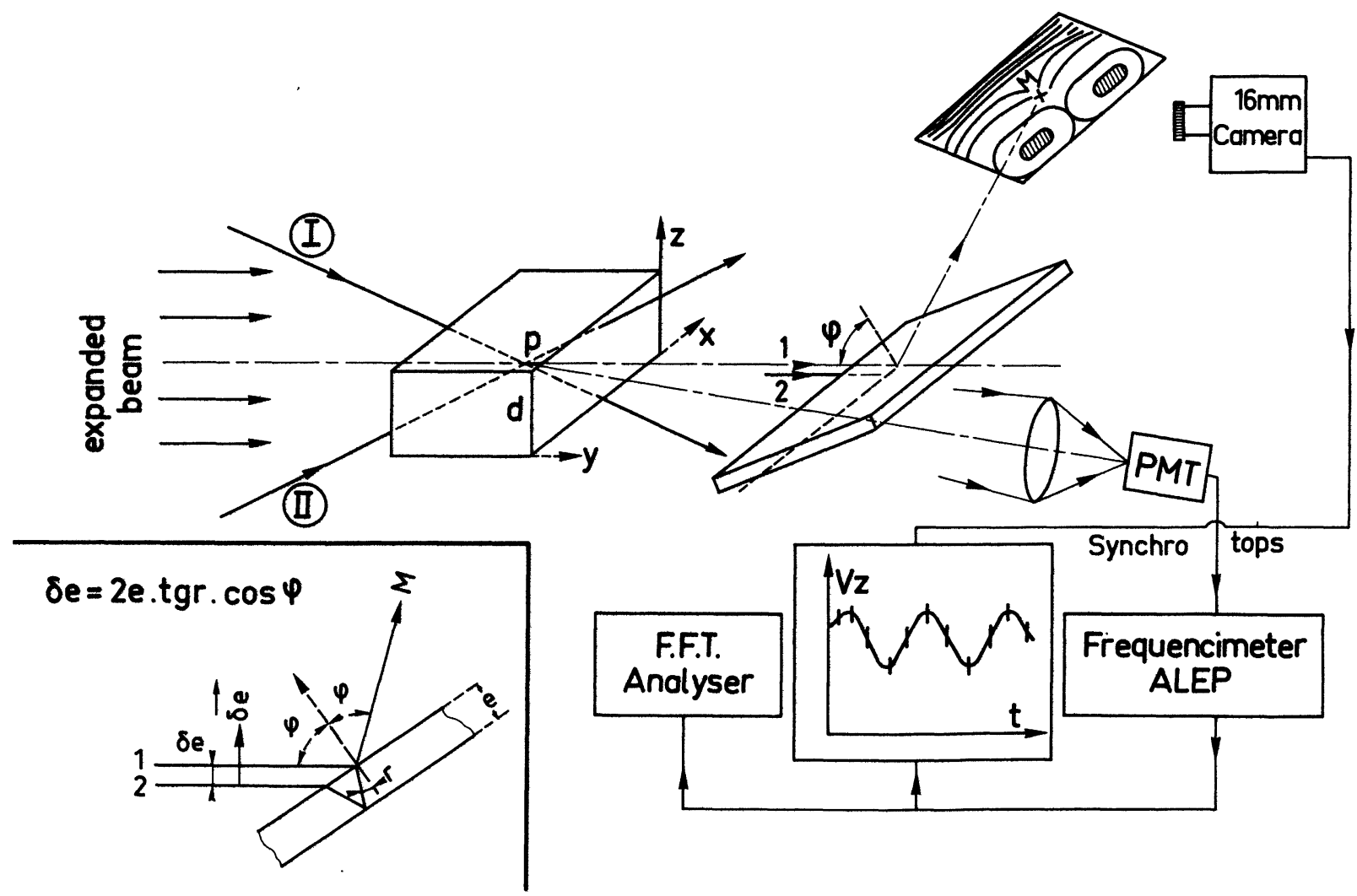

Fig. 2. - Scheme of the optical set up I and II are the two narrow beams of the Doppler velocity meter. P is the point where the velocity is measured. PMT is the photomultiplier which receives the light scattered from P. G is the glass plate which recombines pairs of rays such as 1 and 2. An enlarged part is shown at the left of the figure; $n$ is the perpendicular to the glass plate. 
A $5 \mathrm{~mW}$ He-Ne laser beam is expanded, crosses the convective fluid and is then reflected by both faces of a glass plate, plane and parallel to $\lambda$. At each point in the field after the glass plate, two rays 1 and 2 interfere after having crossed the fluid under study along two nearby paths separated by $\delta e$. The interference order is proportional to the difference between the mean refractive indexes, and therefore to the difference between the mean temperatures of the two paths. By imaging, we then obtain the map of the absolute value of the temperature derivative in the $\delta e$ direction. In practice, we choose $\delta e$ to be parallel to $X^{\prime} X$ or $Z^{\prime} Z$. $\delta e$ can easily be adjusted through the width $e$ of the glass plate (here, $e=2 \mathrm{~mm}$ ) and the angle $\varphi$. Furthermore, the presence of the glass plate, near the exit of the cell, does not perturb in any way the laser Doppler velocimeter, which works simultaneously at the same place. The simplicity of this set-up leads to a very appealing costefficiency ratio.

Convective structure. - Some examples of the results are shown in figure 3 . They show the velocity field and the isogradient lines of the convective motion established in the previously described cell for $\frac{R a}{R a_{\mathrm{c}}} \simeq 143\left(^{2}\right)$. The motion is stationary and the convective structure can be described by the superposition of two rolls along the $X^{\prime} X$ direction and two rolls along the $Y^{\prime} Y$ direction [the dependence $V_{z}=f(Y)$ at $X=L_{x} / 2$ is quite similar to that of $V_{z}=f(X)$ shown in the figure], perturbed by boundary effects. The isogradient lines, projected on the $[Z, X]$ plane, confirm qualitatively the velocimetry results, although the interference order is related to the integration along the $Y^{\prime} Y$ direction, and it is difficult, in the case of three dimensional motions, to calculate the local temperature perturbation. However, the hot region at the bottom of the layer, which is characteristic of an ascending motion [14], can be noticed, particularly in the horizontal isogradients picture. [The same kind of picture is observed along the $Y^{\prime} Y$ direction.]

Oscillatory regime. - The main interest of this temperature visualisation is to allow the instantaneous determination of the whole structure in unsteady motion, while velocimetry gives more quantitative, but local information.

For a given fluid, the threshold of the time dependent phenomena depends on the dimensions of the layer and in a small box $(\Gamma=2)$, time independent convection may be observed up to more than many hundred times the critical onset, with a fluid having a Prandtl number of 130 ; this threshold also strongly depends on the actual convective structure.

( $\left.{ }^{2}\right) R a_{\mathrm{c}}$ is the threshold in infinite geometry i.e. $R a_{\mathrm{c}}=1707$
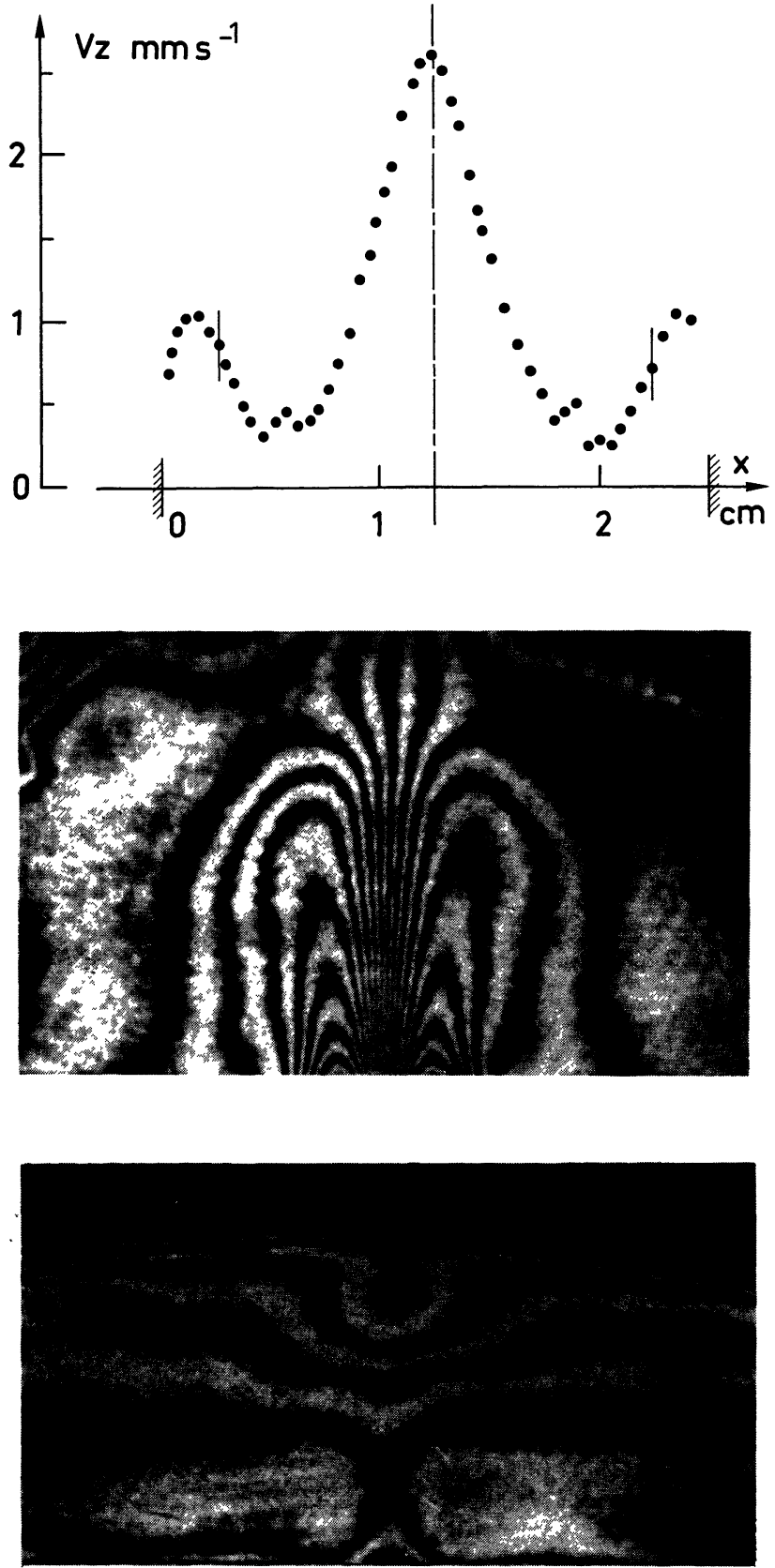

Fig. 3. - Dependence of the $V_{z}$ component with $X$ measured at the mid-height of the cell $(Z=d / 2)$ and at $Y=L_{y} / 2 . R a / R a_{\mathrm{c}}=143$ In I and II, corresponding isogradient lines : I - horizontal isogradient lines with $(\delta e)_{x}=1.53 \mathrm{~mm}$. II - vertical isogradient lines with $(\delta e)_{z}=0.65 \mathrm{~mm}$.

The simplest unsteady state, which may be obtained, corresponds to the periodic time dependence of the velocity; although this has been observed in many different systems $[9,11,15,16,17]$, up to now, no definitive mechanism has been brought to light. So let us analyse the physical data obtained in this oscillatory regime through simultaneous velocity and interferometric measurements, with $R a / R a_{\mathrm{c}}=280$.

The time dependence of the velocity component $V_{z}$, measured at $z=d / 2$, in the maximum ascending motion is shown in figure $4 a$. This oscillatory regime 


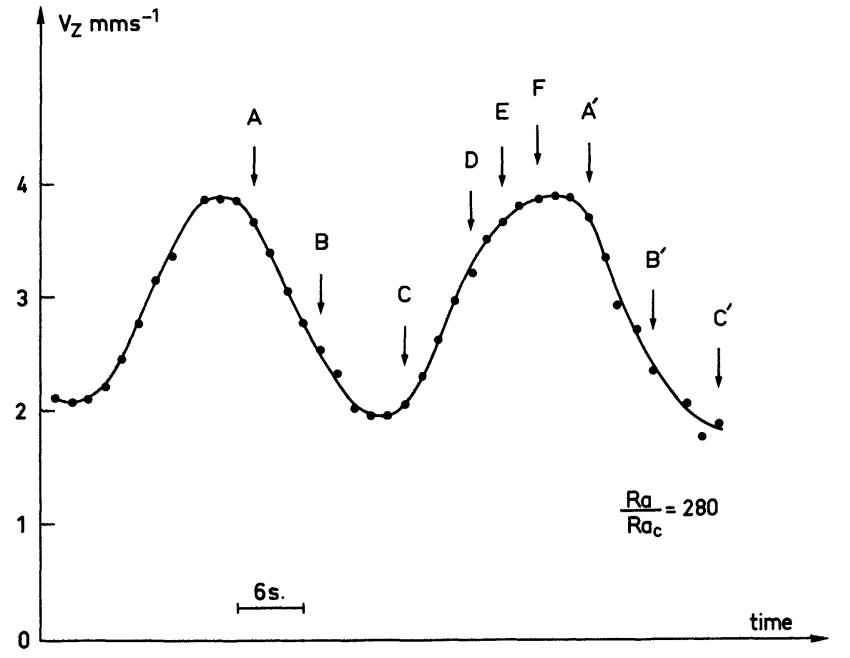

a)
A

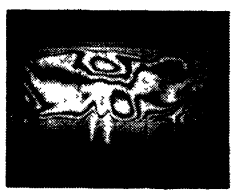

D

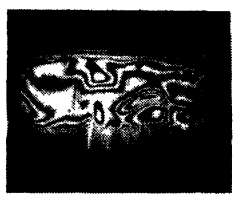

$A^{\prime}$

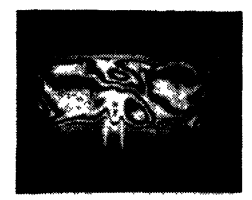

B

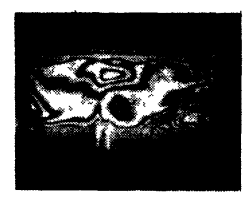

$\mathbf{E}$

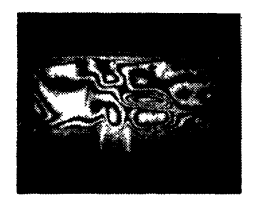

$\mathbf{B}^{\prime}$

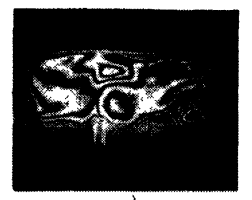

b)
Fig. 4. - $-a$ ) Time dependence of the $V_{z}$ component measured at the maximum ascending flow $Z=d / 2$ and $Y \simeq L_{y} / 2 . R a / R a_{\mathrm{c}}=280$. b) Photographs of the most representative vertical isogradient lines $\left[\left(\delta e_{z}\right)=0.65 \mathrm{~mm}\right]$ taken simultaneously with the velocity measurements at A, B... and so on. Practically a complete cycle is representated from $A$ to $\mathbf{A}^{\prime} . \mathbf{A}^{\prime}, \mathbf{B}^{\prime}$ and $\mathbf{C}^{\prime}$ correspond to the same phase as $\mathrm{A}, \mathrm{B}$ and $\mathrm{C}$. The respective times $\left(t_{\mathrm{A}}\right.$ being taken as the origin) of the images are : $t_{\mathrm{B}}=6 \mathrm{~s} ; t_{\mathrm{C}}=14 \mathrm{~s} ; t_{\mathrm{D}}=20 \mathrm{~s}$; $t_{\mathrm{E}}=23 \mathrm{~s} ; t_{\mathrm{F}}=26 \mathrm{~s} ; t_{\mathrm{A}^{\prime}}=30 \mathrm{~s} ; t_{\mathrm{B}^{\prime}}=36 \mathrm{~s} ; t_{\mathrm{C}^{\prime}}=44 \mathrm{~s}$. Here, the hot droplet originates in a right lower corner (see A, B) and is advected at $C ; D, E$ and $F$ show 3 steps in the advection by the roll.

can be maintained for several weeks and is characterized by a velocity power spectrum with a very narrow frequency peak (here, $f_{0}=33 \times 10^{-3} \mathrm{~s}^{-1}$ ) together with its harmonics $n f_{0}$. Simultaneously, the images of the isogradient lines are filmed $(16 \mathrm{~mm}$ camera) at the rate of 1 image per second. Synchro- nisation marks give the correspondance between each image and the measured $V_{z}$ amplitude. In figure $4 b$, we present some selected images corresponding to the more representative steps of the oscillatory cycle (projected on an $X Z$ plane).

Observations and proposed mechanism. - The observed results, as shown in figure 4, can be summarized as follows : there are schematically two main phases in a complete cycle. The first one corresponds to the growing of a hot droplet. The second stage corresponds to the advection of this droplet, together with the increase in velocity amplitude. During its advection, the droplet relaxes thermally, and then disappears with a reduction in the velocity field amplitude.

In order to gain a good understanding of the observed behaviour, it is necessary to examine the known velocity field, together with the isogradient images. The hot droplet, which grows on the bottom plate, and in a corner of the small box, is initially, in a region of very low velocity (see fig. 1), where the heat flux is not yet well advected. During its growth, the droplet has no perceptible horizontal motion; after a while, it reaches its final extension $b$ (here, $b \simeq 2 \mathrm{~mm}$ ).

At the end of its growth, the droplet becomes unstable and reaches a region where the horizontal velocity is high $\left(V_{x}\right.$ is maximum at $\left.Z=0.2 d\right)$ [1]. So, it is completely advected. The hot, less dense, droplet obviously acts as an additional force in the convective ascending motion and the velocity field - and thus the vertical mass flux - is highly enhanced; moreover, the passage of the droplet in the ascending motion gives rise to a deformation in the convective structure. This last point can easily be seen on the « F » image and is checked by velocity measurements at different points in the structure. During its advection, the droplet relaxes thermally and a new cycle follows.

This mechanism is principally governed by a local thermal singularity, itself controlled by the thermal diffusivity of the fluid; note that there is good agreement between the growth time of the droplet ( $\sim 15 \mathrm{~s}$.$) , the half of the oscillating period, and the$ thermal diffusivity time $b^{2} / 4 D_{\mathrm{T}}$. To some extent, this mechanism can be compared to that proposed by Howards [18], which is related to an instability in the sublayer and leads to the law [19]

$$
\tau_{\mathrm{osc}} \div \frac{d^{2}}{D_{\mathrm{T}}}\left(\frac{R a}{R a_{\mathrm{c}}}\right)^{-0.66}
$$

also obeyed in small boxes. In each periodic situation, observed here at $R a / R a_{\mathrm{c}} \simeq 280$, we always observed only one droplet, in spite of the presence of four (equivalent at first sight) corners. Nevertheless, in different experiments performed with the same small cell, the droplet did not originate in the same corner. 
When an ascending motion is present in the centre of the cell (Fig. 1), a hot droplet may be formed in any bottom corner; when a descending motion is present in the centre of the cell (opposite situation to that in figure 1), a cold droplet may be formed in any top corner. The increased degeneracy originates from a slight dissymmetry in the structure, the unstable corner being that of the largest roll (the actual lowest wavenumber). In contrast, we notice that in a perfectly symmetrical structure (rolls of the same size), we did not observe either droplets, or oscillations, until $R a \simeq 420 R a_{\mathrm{c}}$.

Furthermore, in large boxes, we observed the same law to be obeyed (1) $\tau_{\text {osc }}=f(R a)$, as in small ones. In large boxes, the presence of structure defects - (local distorsions of the wavelength leading to large regions where $V$ is very small [20]) can probably play locally the same role as the boundaries of the small box considered in this paper; so we believe the mechanism to be the same as in small boxes.

In conclusion, the simultaneity of velocity and interferometric measurements (performed in a simple manner) has allowed the physical mechanism responsible for periodic behaviour in convective high Prandtl number fluid to be understood; from our observations, it now seems clear that this behaviour is governed by the growth of a local temperature heterogeneity.

Acknowledgments. - We wish to thank G. Zalczer and Y. Pomeau for helpful discussions and B. Ozenda and $M$. Labouise for their technical assistance contributions.

\section{References}

[1] Dubois, M. and Bergé, P., J. Fluid Mech. 85 (1978) 641.

[2] Wesfreid, J., Pomeau, Y., Dubois, M., Normand, C. and Bergé, P., J. Physique 39 (1978) 725.

[3] Fenstermacher, P. R. and Swinney, H. L., Benson, S. V. and Gollub, J. P., in Bifurcation Theory in Scientific Disciplines, edited by O. Gürel and O. Rössler (N.Y. Academy of Sciences) 1978.

[4] FarhadieH, R. and TANKIN, R. S., J. Fluid Mech. 66 (1974) 739.

[5] MORDCHELles-RÉGNIER, G. and KaPlaN, C., Les Instabilités en Hydraulique et en Mécanique des Fluides, Lille 1964, p. 91 (La Houille Blanche-Grenoble).

[6] Bryngdaht, O., J. Opt. Soc. Amer. 53 (1962) 571.

[7] Oer Tel, H. and BüHLER, K., Int. J. Heat Mass Transfer 21 (1978) 1111.

[8] Oertel, H. and Kirchartz, K. R., Appl. Opt. 17 (1978) 3535.

[9] Gollub, J. P. and Benson, S. V., Phys. Rev. Lett. 41 (1978) 948.

[10] DuBors, M. and Bergé, P., Far from Equilibrium Bordeaux Sept. 1978, To be published by (Springer-Verlag) Janv. 1979.

[11] Ahlers, G. and Behringer, R. P., Phys. Rev. Lett. 40 (1978) 712 .
[12] LibChaber, A. and MaURer, J., J. Physique Lett. 39 (1978) L-369.

[13] Bergé, P., Fluctuations, Instabilities and Phase Transitions NATO Advanced Study Institutes (Plenum Press) Vol. B11 (1975) 323.

[14] Nataf, H. C., Private communication.

[15] Krishnamurti, R., J. Fluid Mech. 60 (1973) 285.

[16] Busse, F. H. and WhiteHEAD, J. A., J. Fluid Mech. 66 (1974) 67.

Whitehead, J. A. and Parsons, B., Geophys. Astrophys. Fluid Dynamics 9 (1978) 201.

[17] Willis, G. E. and DeardorfF, J. W., J. Fluid Mech. 44 (1970) 661 .

[18] Howard, L. N., Proc. 11th Congr. Appl. Mech. (SpringerVerlag) 1966, p. 1109.

[19] Bergé, P. and DuBors, M., Opt. Commun. 19 (1976) 129.

[20] Bergé, P., Proceedings of CDC 79 (Genève April 79) to appear (Springer-Verlag). 